\title{
Transcatheter pulmonary valve implantation in 100 patients: a 10-year single-center experience
}

\author{
Witold Rużyłło ${ }^{1}$, Elżbieta K. Biernacka², Olgierd Woźniak², Mirosław Kowalski², Mateusz Śpiewak², \\ Alicja Cicha-Mikołajczyk ${ }^{4}$, Aleksander Szczęsny², Mariusz Kuśmierczyk ${ }^{5}$, Piotr Hoffman², Marcin Demkow ${ }^{1}$ \\ ${ }^{1}$ Department of Coronary and Structural Heart Diseases, The Cardinal Stefan Wyszyński National Institute of Cardiology, Warsaw, Poland \\ ${ }^{2}$ Department of Congenital Heart Diseases, The Cardinal Stefan Wyszyński National Institute of Cardiology, Warsaw, Poland \\ ${ }^{3}$ Department of Radiology, The Cardinal Stefan Wyszyński National Institute of Cardiology, Warsaw, Poland \\ ${ }^{4}$ Department of Epidemiology, Cardiovascular Disease Prevention and Health Promotion, The Cardinal Stefan Wyszyński National Institute \\ of Cardiology, Warsaw, Poland \\ ${ }^{5}$ Department of Cardiac Surgery and Transplantology, The Cardinal Stefan Wyszyński National Institute of Cardiology, Warsaw, Poland
}

Adv Interv Cardiol 2020; 16, 3 (61): 235-243

DOI: https://doi.org/10.5114/aic.2020.99257

\section{A bstract}

Introduction: Transcatheter pulmonary valve implantation (TPVI) is a non-surgical method of treatment for patients with right ventricular outflow tract (RVOT) dysfunction after surgical repair of congenital heart defects (CHD).

Aim: To evaluate the long-term results of TPVI performed in a single center.

Material and methods: Over 10 years, TPVI was performed in 100 patients (mean age: $26.4 \pm 8.1$ years), using Melody Medtronic or Sapien Edwards valves.

Results: The initial success rate of TPVI was $93 \%$. In 7 cases (5 urgent), a switch to surgical intervention was necessary due to periprocedural complications (all patients survived). Following TPVI, none of the 93 patients had severe pulmonary regurgitation. The pulmonary gradient decreased from $49.0 \pm 37.8$ before to $27.6 \pm 14.9 \mathrm{~mm} \mathrm{Hg}$ directly after TPVI $(p<0.0001)$. Right ventricular end-diastolic volume decreased, while NYHA class and $\mathrm{pVO}_{2}$ uptake significantly improved in 1 year after TPVI. Freedom from reintervention was $100 \%$ in 1 year. Freedom from serious adverse events was $86 \%$ in mean 5.5 years of observation. The main reason for reintervention was infective endocarditis (IE) (1.6\% patients/year). Increased risk of IE was associated with severe PS before valve implantation and the suboptimal result of TPVI. The incidence of IE seems to be lower in patients treated permanently with antiplatelet therapy (1.8\% vs. $0.9 \%$ patients/year, NS).

Conclusions: TPVI is a safe and effective method of treatment in patients with RVOT dysfunction after surgical correction of CHD. To achieve a good outcome, precise patient selection and rigorous IE prevention are necessary.

Key words: congenital heart disease, pulmonary stenosis, pulmonary regurgitation.

Su m m a ry

The results of one-center transcatheter pulmonary valve implantation (TPVI) in 100 adults following surgical repair of congenital heart defects (CHD) are presented. There was no periprocedural mortality. In 7 cases, surgical intervention was necessary. Valve competence was restored in most patients. Maximal pulmonary gradient decreased significantly. Right ventricular end-diastolic volume decrease, NYHA class and $\mathrm{VO}_{2}$ uptake improved in 1 year after TPVI. Freedom from reintervention was $100 \%$ in 1 year and from serious adverse events $86 \%$ in mean 5.5 years of observation. TPVI is a safe and effective method of treatment in ventricular outflow tract dysfunction after surgical correction of CHD.

\section{Introduction}

Transcatheter pulmonary valve implantation (TPVI) is a less invasive alternative to reoperation of right ven- tricular outflow tract (RVOT) dysfunction in patients after surgical repair of congenital heart defects (CHD). Several studies show the noninferiority of the percutaneous

\section{Corresponding author:}

Prof. Witold Rużyłło MD, PhD, Department of Coronary and Structural Heart Diseases, The Cardinal Stefan Wyszyński National Institute of Cardiology, 42 Alpejska St, 04-628 Warsaw, Poland, phone: +48 601228 632, e-mail: wruzyllo@ikard.pl

Received: 12.08 .2020 , accepted: 30.08.2020. 
Table I. Patient characteristics

\begin{tabular}{|c|c|}
\hline Parameter & Results \\
\hline Number of patients & 100 \\
\hline Gender (male), $n=\%$ & 53 \\
\hline Age at TPVI, mean \pm SD [years] & $26.4 \pm 8.1$ \\
\hline \multicolumn{2}{|l|}{ Congenital heart defect, $n=\%$ : } \\
\hline ToF & 65 \\
\hline PA, VSD & 15 \\
\hline TGA, VSD & 5 \\
\hline Aortic stenosis (Ross procedure) & 7 \\
\hline Other & 8 \\
\hline Time since last procedure, mean \pm SD [years] & $17.5 \pm 7.5$ \\
\hline Procedures, $n$, mean \pm SD & $2.2 \pm 1.2$ \\
\hline Operations, $n$, mean \pm SD & $1.9 \pm 0.9$ \\
\hline \multicolumn{2}{|l|}{ RVOT reconstruction, $n=\%$ : } \\
\hline Pulmonary homograft & 33 \\
\hline Aortic homograft & 8 \\
\hline Xenograft & 3 \\
\hline Patch & 56 \\
\hline \multicolumn{2}{|l|}{ RVOT dysfunction: } \\
\hline Predominant pulmonary stenosis & 25 \\
\hline Predominant pulmonary regurgitation & 43 \\
\hline Combined lesions & 32 \\
\hline \multicolumn{2}{|l|}{$\mathrm{ECHO}(n=100)$} \\
\hline Pulmonary gradient, mean $\pm \mathrm{SD}[\mathrm{mm} \mathrm{Hg}]$ & $49.7(38.0)$ \\
\hline \multicolumn{2}{|l|}{ Pulmonary stenosis, $n=\%$ : } \\
\hline Severe, $\mathrm{PG}>64 \mathrm{~mm} \mathrm{Hg}$ & 28 \\
\hline Moderate, $\mathrm{PG}>35 \mathrm{~mm} \mathrm{Hg}$ & 27 \\
\hline Mild/none & 45 \\
\hline \multicolumn{2}{|l|}{ Pulmonary regurgitation, $n=\%$ : } \\
\hline None, trivial & 16 \\
\hline Mild & 9 \\
\hline Moderate & 20 \\
\hline Severe & 55 \\
\hline \multicolumn{2}{|l|}{ Tricuspid regurgitation, $n=\%$ : } \\
\hline None, trivial & 27 \\
\hline Mild & 54 \\
\hline Moderate & 17 \\
\hline Significant, severe & 2 \\
\hline \multicolumn{2}{|l|}{ MRI $(n=83)$} \\
\hline \multicolumn{2}{|l|}{ Pulmonary regurgitation, $n(\%)$ : } \\
\hline None, trivial & $13(16)$ \\
\hline Mild & $16(19)$ \\
\hline Moderate & $15(18)$ \\
\hline Severe & $39(47)$ \\
\hline Pulmonary regurgitation fraction (\%), mean \pm SD & $31.1 \pm 16.7$ \\
\hline RVEDVI, mean $\pm \mathrm{SD}\left[\mathrm{ml} / \mathrm{m}^{2}\right]$ & $156.3 \pm 42.5$ \\
\hline RVEF (\%), mean $\pm S D$ & $46.4 \pm 9.2$ \\
\hline \multicolumn{2}{|l|}{ NYHA class, $n=\%:$} \\
\hline 1 & 21 \\
\hline II & 57 \\
\hline III & 22 \\
\hline IV & 0 \\
\hline Peak $\mathrm{VO}_{2}$, mean $\pm \mathrm{SD}(n=74)$ & $23.4 \pm 6.9$ \\
\hline \multicolumn{2}{|c|}{$\begin{array}{l}\text { MRI - magnetic resonance imaging, } n \text { - number of patients with data avail- } \\
\text { able, PA - VSD - pulmonary atresia and ventricular septum defect, peak VO } \\
\text { - maximal oxygen uptake, } P G \text { - pulmonary gradient, ToF - tetralogy of Fallot, } \\
\text { TPVI - transcatheter pulmonary valve implantation, RVEDVI - right ventricular } \\
\text { end-diastolic volume index, RVEF-right ventricular ejection fraction, SD - stan- } \\
\text { dard deviation, TGA - VSD - transposition of great arteries with VSD. }\end{array}$} \\
\hline
\end{tabular}

method to the surgical procedure in in-hospital and short-term observations. Long-term outcomes of this relatively new procedure need more assessment.

Due to a small number of patients being qualified for the transcatheter procedure, published results are usually multicenter and focused on only one of two types of the valve. To our best knowledge, we are the first to report a group of one hundred patients who underwent TPVI in one center during a period of 10 years using both Melody Medtronic (MM) and SAPIEN Edwards (SE) valves [1].

\section{Aim}

The aim of the study was to examine in-hospital, mid-term, and long-term results of TPVI performed using the MM and SE valves in patients with RVOT dysfunction. Additionally, we wanted to assess valve durability in the long-term observation and identify predictors of favorable prognosis, which would allow for better patient selection for the procedure.

\section{Material and methods}

The study group consisted of 100 consecutive patients (age 13-58, mean: $26.4 \pm 8.1$ years, 53 males), with RVOT dysfunction following surgical repair of CHD who underwent TPVI in our center between December 2008 and March 2019 (patient demographic and clinical characteristics are summarized in Table I). The most common underlying diagnoses were tetralogy of Fallot (65\%) and pulmonary atresia (15\%), followed by aortic stenosis corrected by the Ross procedure (7\%), transposition of the great arteries (TGA) after Rastelli or the REV (Réparation à l'Etage Ventriculaire) procedure (5\%) and other CHD (8\%): double outlet right ventricle (DORV), common arterial trunk type 1 (CAT I), pulmonary stenosis (PS), and double outlet left ventricle (DOLV).

The last surgical repair had been performed using a full conduit in 44 patients (pulmonary homograft 33\%, aortic homograft $8 \%$, Contegra $3 \%$ ) and with a transannular patch in 56 patients. There were no patients with degraded bioprosthetic valves. The average interval from the last surgery to TPVI was $17.5 \pm 7.5$ years.

Indications for the procedure were consistent with the European guidelines relating to surgical pulmonary valve implantation [2]. Severe pulmonary regurgitation (PR) was seen in 55 patients, moderate in 20, mild in 9, and trivial or none in 16 . The maximal pulmonary gradient (MPG) was severely increased (> $64 \mathrm{~mm} \mathrm{Hg}$ ) in 28 patients, moderate (36-64 $\mathrm{mm} \mathrm{Hg}$ ) in 27 , and mild or none in 45. Most of the patients were in NYHA class I and II, while $22 \%$ were in class III (Table I).

\section{Study design}

Preprocedural screening and post-procedural follow-up assessment included: clinical examination, 12lead ECG, chest radiographs, transthoracic echocardiog- 
raphy (ECHO), the cardiopulmonary exercise test (CPET) (annually) and cardiac magnetic resonance imaging (MRI) before the procedure, then 1 month (in the first 47 patients), 1 year, 3-4 years and 8-10 years after TPVI. Death, reoperation, transcatheter reintervention, or infective endocarditis (IE) related to the pulmonary valve were considered to be a significant adverse event (SAE).

Echocardiography was performed using a Vivid E9 ultrasound system (GE Medical Systems, Milwaukee, USA) in all patients. A continuous wave Doppler was used to measure the peak instantaneous pressure gradient across the RVOT at the parasternal short-axis view. The calculation was made on the basis of the Bernoulli equation. Pulmonary regurgitation was qualitatively assessed by color Doppler and graded as none, mild, or significant using visual inspection of the width of the regurgitant jet in relation to the outflow tract diameter $(<25 \%=$ mild). The tricuspid valve was visualized in the parasternal short-axis view and the apical four-chamber view; the jet of tricuspid regurgitation (TR) was assessed by color Doppler. The grading of TR severity was based on assessments of the jet area, density, and vena contracta. Peak velocity was obtained by tracing the envelope, which was automatically converted to gradient by machine. Systolic right ventricular pressure was calculated by adding the right atrial pressure to the peak gradient.

Cardiac MRI was performed in 85 patients prior to TPVI and in 83 patients during follow-up. In 47 patients, an MRI was also performed 1 month after the procedure. Several patients did not undergo follow-up cardiac MRI due to contraindications: claustrophobia, pacemaker, ferromagnetic implants. All MRI studies were performed using a $1.5 \mathrm{~T}$ scanner (Avanto/Avanto fit, Siemens, Erlangen, Germany). Ventricular volumes were calculated based on a stack of short-axis cine images covering both ventricles from the base to the apex. Right ventricle end-diastolic volume (RVEDV) and right ventricle ejection fraction (RVEF) were calculated using dedicated software (MASS, 6.2.1 or later, Medius, Leiden, the Netherlands). All volume parameters were indexed for body surface area and expressed in $\mathrm{ml} / \mathrm{m}^{2}$. Pulmonary regurgitation fraction (PRF) was calculated as a percentage of backward flow over forward flow, which corresponded to mild (PRF 10-20\%), moderate (PRF 20-35\%), or severe (PRF $>35 \%)$ pulmonary regurgitation.

\section{Valves}

Melody Medtronic (Minneapolis, USA) mounted on an 18 , 20, or $22 \mathrm{~mm}$ Ensemble delivery system or Edwards transcatheter heart valves: Edwards SAPIEN 23, $26 \mathrm{~mm}$ with the RetroFlex delivery system, SAPIEN XT 23, 26, $29 \mathrm{~mm}$ with the NovaFlex delivery system, and SAPIEN 3, 26 and $29 \mathrm{~mm}$ with the Commander Delivery System (Edwards Lifesciences LLC, Irvine, CA).

The procedure was preceded by precise patient evaluation regarding indications for pulmonary valve im- plantation and anatomy of RVOT. At the time of TPVI, an ongoing infection was excluded in each subject. Periprocedural antibiotics, primarily cefazolin, were administered at all times within $4 \mathrm{~h}$ before the procedure.

All the procedures were performed under general anesthesia with endotracheal intubation. The femoral vein (in 3 cases the jugular vein) was used for access. Cardiac catheterization with assessment of the right heart, pulmonary and aortic pressures, and coronary angiography with balloon inflation at the planned implantation site, preceded each procedure. Balloon sizing was performed to determine RVOT diameter. All patients underwent routine prestenting of the target site with a bare metal stent (IntraStent Max LD, ev3 Endovascular, Plymouth, USA, or AndraStent Andramed $\mathrm{GmbH}$, Reutlingen, Germany). In 33 patients with no waist after prestenting of the borderline-large outflow tract, the valve implantation was delayed for 2 months to allow for stent fixation as the result of tissue ingrowth.

The choice of a valve depended on RVOT dimensions. In patients with a narrow RVOT, Melody valves were implanted (maximal available valve size $22 \mathrm{~mm}$ ), while in patients with a wider RVOT (landing zone exceeding $22 \mathrm{~mm}$ ), SE valves were chosen. Hemodynamic and angiographic evaluations were repeated following valve deployment. For the hemostasis at the venous access site, a single Z-stitch was put on the skin. Manual compression was applied for the arterial access site.

The antiplatelet treatment schedule has been changed twice since the first valve was implanted: until the year 2010 acetylsalicylic acid (ASA) was administered for 6 months, then in the years 2011-2013 ASA and clopidogrel for 6 months (51 patients), and since 2014 ASA lifelong and clopidogrel for 6 months.

The protocol of valve implantation was approved by the local Ethics Committee. Informed consent for the procedure was obtained from all patients or their legal representatives.

\section{Statistical analysis}

Data are presented as mean (standard deviation) or median (interquartile range) for quantitative variables and numbers (percentages) for qualitative variables. The normality of data distribution was tested using the Shapiro-Wilk test. Generalized linear mixed models were applied for the analysis of time-dependent outcome variables (RVEF, indexed RVEDV, pulmonary gradient, and peak oxygen uptake). A two-tailed $p$-value $<0.05$ was considered significant. All statistical analyses were performed using SAS 9.4 (Cary, NC, USA).

\section{Results}

\section{Procedural results}

Over 10 years, TPVI was performed in 100 patients ( $M M$ - 49 patients, SE - 51 patients), with no periprocedural mortality (Table II). The procedural success rate was 
93\%. Mean procedure time was $165.7 \pm 37.7$ min, fluoroscopy time $28.2 \pm 11.9 \mathrm{~min}$. The mean hospital stay after successful TPVI was $84.4 \pm 32.2$ h. No significant vascular access site complications were observed.

In 7 cases, surgical intervention was necessary (5 urgent, 2 elective). In 2 patients during delivery of the SE XT valve the system was entangled in the tricuspid

Table II. Procedure characteristics

\begin{tabular}{|c|c|}
\hline Parameter & Results \\
\hline Two-stage procedure, $n=\%$ & 33 \\
\hline \multicolumn{2}{|l|}{ Valve, $n=\%$ : } \\
\hline Melody Medtronic (MM) & 49 \\
\hline Sapien Edwards (SE) & 51 \\
\hline \multicolumn{2}{|l|}{ Valve size $[\mathrm{mm}], n=\%$ : } \\
\hline $18(\mathrm{MM})$ & 5 \\
\hline $20(\mathrm{MM})$ & 7 \\
\hline $22(\mathrm{MM})$ & 37 \\
\hline 23 (SE) & 6 \\
\hline 26 (SE) & 24 \\
\hline 29 (SE) & 21 \\
\hline \multicolumn{2}{|l|}{ SE type, $n=\%$ : } \\
\hline SE & 17 \\
\hline SE XL & 18 \\
\hline SE S3 & 16 \\
\hline Time of procedure, mean \pm SD [min] & $165.7(37.7)$ \\
\hline Time of fluoro, mean \pm SD [min] & $28.2(11.9)$ \\
\hline Severe procedural complications, $n=\%$ : & 7 \\
\hline Urgent surgery & 5 \\
\hline Elective surgery & 2 \\
\hline Hospitalization (time), mean \pm SD [h] & $84.4(32.2)$ \\
\hline
\end{tabular}

A

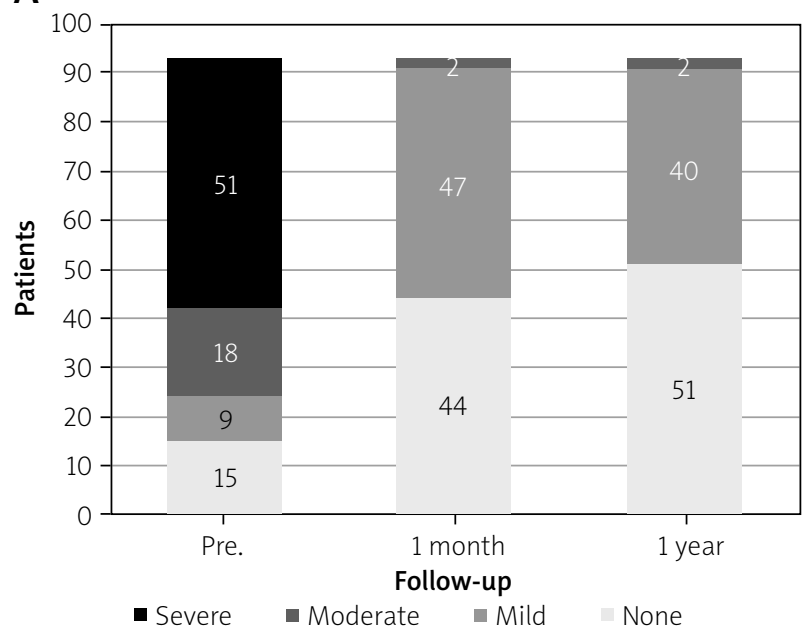

valve, resulting in difficulty in pulling out the system. Valve or stent migrations were observed in 2 patients with a patched borderline large RVOT $(29 \mathrm{~mm})$. Homograft dissection $(n=2)$ in 1 case was stable hemodynamically and operated on a few days later, while in a second patient an urgent operation was needed. There was one case (in a patient after REV operation) where the valve was compressed by severe anterior calcification of the RVOT 1 day after the implantation [3]. All surgical interventions were successful.

Follow-up comprised 93 patients after successful TPVI. None of them had severe PR; it was none or trivial in 45 patients, mild in 46 patients, and moderate in 2 patients (Figure 1 A). MPG decreased from $49.0 \pm 37.8 \mathrm{~mm} \mathrm{Hg}$ before to $27.6 \pm 14.9 \mathrm{~mm} \mathrm{Hg}$ one day after TPVI ( $p<$ $0.0001)$. In 26 patients with severe pulmonary stenosis, MPG decreased from $96.6 \pm 31.0 \mathrm{~mm} \mathrm{Hg}$ before to 40.9 $\pm 18.0 \mathrm{~mm} \mathrm{Hg}$ one day after TPVI $(p<0.0001)$ (Figure $1 \mathrm{~B}$, Table III).

\section{One-month results (Table III)}

As soon as at 1 month, 51 patients reported improvement of exercise tolerance (NYHA class $1.35 \pm 0.59$ vs. 1.9 \pm 0.7 before the procedure, $p<0.0001$ ) (Figure $2 \mathrm{~A}$ ). A further, nonsignificant fall in MPG was observed at 1 month (25.8 \pm 15.0$)$. Two patients with a suboptimal result underwent planned transcatheter balloon dilatation after about 2 months. Magnetic resonance imaging performed in 47 patients 1 month after the procedure showed that indexed right ventricular end-diastolic volume (RVEDVi) decreased significantly from $156.8 \pm 42.8 \mathrm{ml} / \mathrm{m}^{2}$ before to $132.7 \pm 42.8 \mathrm{ml} / \mathrm{m}^{2}(p<0.0001)$ (Figure $2 \mathrm{~B}$ ); improvement of RVEF was nonsignificant in the whole group, and significant in the group of patients with severe pulmonary stenosis $(p=0.0009)$. No stent fractures were seen in chest radiographs.

\section{B}

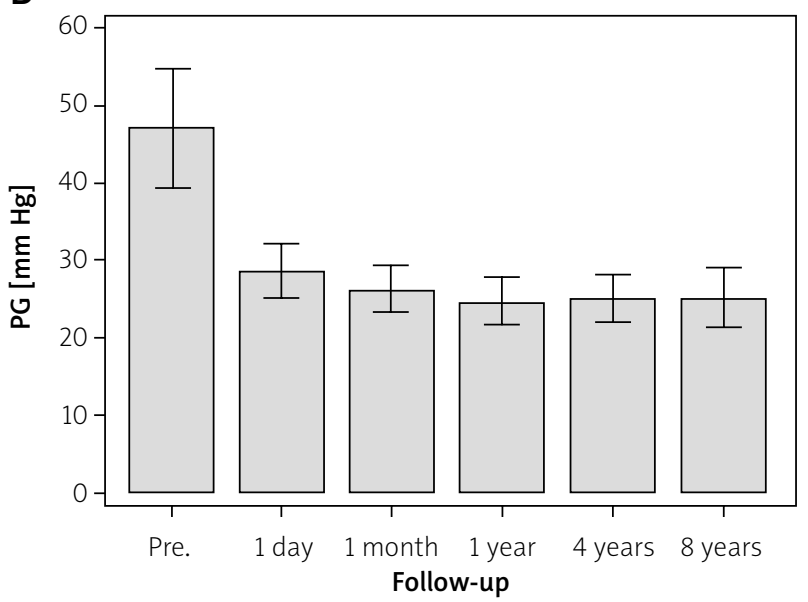

Figure 1. Right ventricular outflow dysfunction before TPVI and short- and long-term results of the procedure: A - pulmonary regurgitation (ECHO), B - pulmonary gradient (ECHO Doppler) 
Table III. Results in 93 patients after successful TPVI

\begin{tabular}{|c|c|c|c|c|c|c|c|}
\hline Parameter & & Pre & 1 day & 1 month & 1 year & $3-4$ years & $8-10$ years \\
\hline \multirow[t]{4}{*}{ PG [mm Hg] (ECHO) } & Mean & 49.0 & 27.6 & 25.8 & 24.9 & 25.1 & 26.9 \\
\hline & SD & 37.8 & 14.9 & 15.0 & 14.7 & 10.7 & 11.1 \\
\hline & No pts & 93 & 93 & 90 & 86 & 54 & 20 \\
\hline & $P$-value & & $<0.0001$ & NS & NS & NS & NS \\
\hline \multirow[t]{4}{*}{$\operatorname{PRF}(\%)^{\star}(M R I)$} & Mean & 37.8 & & 3.5 & 4.7 & & \\
\hline & SD & 13.2 & & 4.3 & 5.3 & & \\
\hline & No pts & 83 & & 47 & 83 & & \\
\hline & $P$-value & & & $<0.0001$ & NS & & \\
\hline \multirow[t]{4}{*}{ RVEDVI [ml/m²] (MRI) } & Mean & 156.8 & & 132.7 & 124.8 & 120.0 & 107.5 \\
\hline & SD & 42.8 & & 42.8 & 39.7 & 32.6 & 31.7 \\
\hline & No pts & 80 & & 47 & 78 & 40 & 12 \\
\hline & $P$-value & & & $<0.0001$ & $<0.0001^{\star \star}$ & NS & NS \\
\hline \multirow[t]{4}{*}{ RVEF (\%) (MRI) } & Mean & 46.4 & & 47.9 & 48.1 & 48.4 & 49.8 \\
\hline & SD & 9.4 & & 10.4 & 9.2 & 10.0 & 11.4 \\
\hline & No pts & 81 & & 47 & 78 & 41 & 12 \\
\hline & $P$-value & & & NS & NS & NS & NS \\
\hline \multirow[t]{4}{*}{$\mathrm{VO}_{2}[\mathrm{ml} / \mathrm{kg} / \mathrm{min}]$} & Mean & 21.4 & & & 24.2 & 25.4 & \\
\hline & SD & 5.9 & & & 5.4 & 6.7 & \\
\hline & No pts & 43 & & & 43 & 43 & \\
\hline & $P$-value & & & & 0.009 & 0.004 & \\
\hline \multirow{4}{*}{$\begin{array}{l}\mathrm{PG}[\mathrm{mm} \mathrm{Hg}](\mathrm{ECHO}) \\
\text { in pts with severe PS }\end{array}$} & Mean & 96.6 & 40.9 & 38.5 & 35.8 & 31.8 & 31.7 \\
\hline & SD & 31.0 & 18.0 & 21 & 22 & 11 & 12 \\
\hline & No pts & 26 & 26 & 26 & 25 & 18 & 11 \\
\hline & $P$-value & & $<0.0001$ & NS & NS & NS & NS \\
\hline \multirow{4}{*}{$\begin{array}{l}\text { RVEDVI }\left[\mathrm{ml} / \mathrm{m}^{2}\right] \\
\text { (MRI), in pts with } \\
\text { severe PS }\end{array}$} & Mean & 121.8 & & 110.6 & 108.4 & 107.1 & 95.9 \\
\hline & SD & 38 & & 33 & 32 & 31 & 24 \\
\hline & No pts & 18 & & 17 & 21 & 14 & 7 \\
\hline & $P$-value & & & 0.014 & NS & NS & NS \\
\hline \multirow{4}{*}{$\begin{array}{l}\text { RVEF (\%) (MRI), in pts } \\
\text { with severe PS }\end{array}$} & Mean & 44.8 & & 52.8 & 52.7 & 50.2 & 51.9 \\
\hline & SD & 13 & & 12 & 10 & 9.8 & 10 \\
\hline & No pts & 19 & & 17 & 21 & 15 & 7 \\
\hline & $P$-value & & & 0.0009 & 0.0027 & NS & NS \\
\hline \multirow{4}{*}{$\begin{array}{l}\mathrm{VO}_{2}[\mathrm{ml} / \mathrm{kg} / \mathrm{min}] \text {, in } \\
\text { pts with severe PS }\end{array}$} & Mean & 21.7 & & & 23.3 & 25.9 & 26.2 \\
\hline & SD & 5.9 & & & 5.4 & 6.8 & 4.2 \\
\hline & No pts & 18 & & & 22 & 17 & 10 \\
\hline & $P$-value & & & & 0.05 & 0.02 & NS \\
\hline
\end{tabular}

MRI - magnetic resonance imaging, PG - pulmonary gradient, PRF - pulmonary regurgitation fraction, RVEDVI - right ventricular end diastolic volume index, RVEF-right ventricular ejection. *PRF difficult to calculate, in most patients PR volume was about 2-3 ml. **Pre-and 1-year comparison. 
A

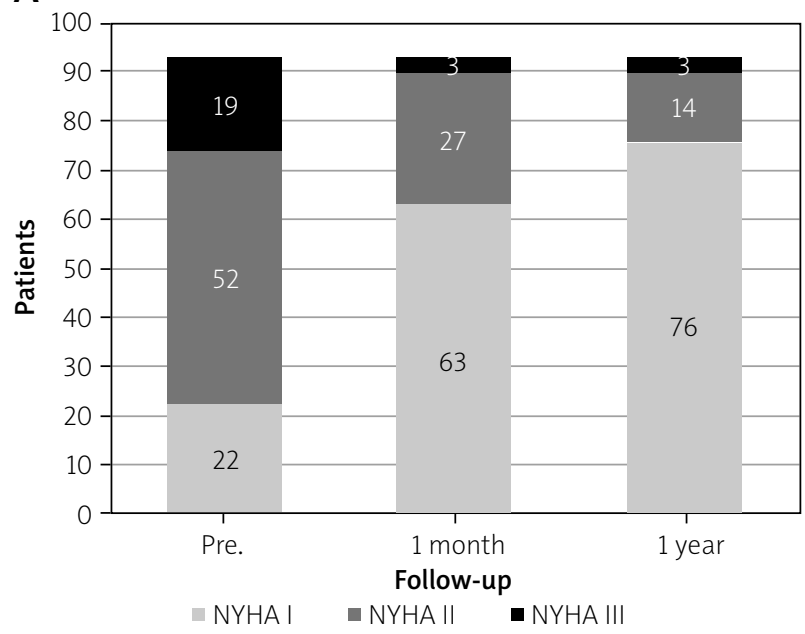

B

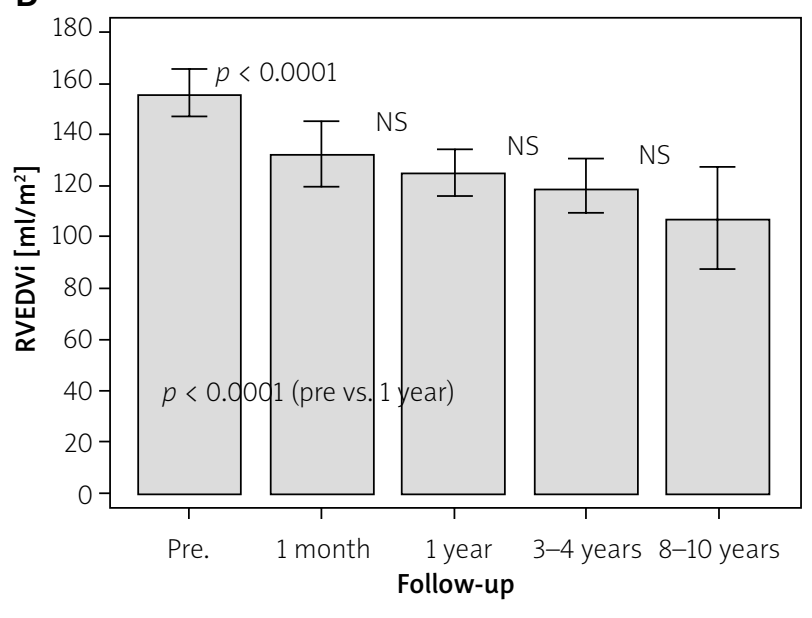

Figure 2. Short- and long-term results of TPVI in 93 patients after successful procedure: A - NYHA class, B right ventricular end diastolic volume

\section{Long-term follow-up}

Follow-up time ranged from 1 to 10 years (mean: 5.5 years). During observation MPG was stable, and the valves remained competent (mild PR: ECHO - 2 cases, MRI -8 cases) (Figures 1 A, B). No stent fractures were seen. RVEDVi improved significantly in 1 year, and no further changes were seen during further observation, either in RVEDVi or RVEF values. The proportion of patients with severe ( 2 patients) and moderate (17 patients) tricuspid regurgitation decreased in 1 year after TPVI (severe -0 , moderate -11 patients).

Most of the patients encompassed by long-term observation were in NYHA class I or II (Figure 2 A). Cardiopulmonary test results showed a slight improvement of peak oxygen uptake in 1 year and in 2-3 year observation in the whole group of patients and significant in the group of 43 patients with complete data $(p=0.009$ and 0.004 , respectively). Significant improvement in maximal exercise capacity was also seen in patients with severe pulmonary stenosis $(p=0.02)$ (Table III).

Seven women gave birth to 8 healthy children 37 years after TPVI. Neither an increase in pulmonary gradient values nor progression of pulmonary regurgitation was observed in any of the women. Their systolic function, RVEDVi, and exercise tolerance remained stable.

\section{Late complications}

In 1-year observation freedom from reintervention was $100 \%$ and from SAE $99 \%$. Freedom from SAE was $86 \%$ in mean 5.5 years of observation (Table IV).

Transcatheter reintervention (MM valve balloon expanding) was performed in 4 patients: in 3 patients because of an increased gradient in the RVOT due to IE, and in another patient after the Ross procedure with a suboptimal result of the $M M$ implantation and rise of pulmonary gradient related to body mass increase.
Finally, after unsuccessful reintervention, the patient was operated on.

IE (diagnosis based on the modified Duke criteria) leading to valve dysfunction was observed in 7 patients (MM - 6 patients, SE -1 patient) (1.6/100 person-years); 2 of them died. Surgical valve explantation was performed in 4 patients. IE had no direct relation to the procedure (median time from TPVI to IE was 35 months). Patients with IE had higher pre- and post-procedural pulmonary gradient (118 \pm 58 vs. $51 \pm 32 \mathrm{~mm} \mathrm{Hg}, p=0.01$ and $28.9 \pm 11.2$ vs. $23.6 \pm 11.3 \mathrm{~mm} \mathrm{Hg}, p=0.001$, respectively). Patients treated with antiplatelet therapy for only 6 months after TPVI had a higher frequency of IE than patients on permanent antiplatelet therapy (1.8\% vs. $0.9 \%$ patient/year). The two groups could not be directly compared due to different follow-ups (median 7.5 vs. 2.1 years, respectively). Notably, the median time from TPVI to IE was 2.5 years. Despite infective endocarditis, none of the patients developed pulmonary valve dysfunction.

\section{Discussion}

Procedural success was achieved in 93\% with no mortality. In other studies, the procedural success rate was similar or slightly better (95\%), but with mortality of $1.5(0.8-2.6) \%[4,5]$. Freedom from reintervention, surgery, or endocarditis in our group was $99 \%$ in 1 year and $85.8 \%$ in mean 5.5 years of observation after TPVI. These results prove that TPVI is effective and can be performed safely in a large percentage of patients with RVOT dysfunction after surgical repair.

\section{Patients and indications}

Our group of patients consisted of about $50 \%$ adolescents and young adults with patched RVOT; therefore, over $50 \%$ of patients presented pulmonary regurgita- 
Table IV. Serious adverse events

\begin{tabular}{|c|c|c|c|c|c|c|c|c|}
\hline Valve & $\begin{array}{l}\text { Lifetime } \\
\text { anti-platelet } \\
\text { therapy }\end{array}$ & $\begin{array}{l}\text { Time } \\
\text { after } \\
\text { TPVI }\end{array}$ & $\begin{array}{c}\text { Valve } \\
\text { dysfunction }\end{array}$ & $\begin{array}{l}\text { Predisposing factors, } \\
\text { pathogen }\end{array}$ & $\begin{array}{l}\text { Only } \\
\text { medical } \\
\text { treatment }\end{array}$ & Re-intervention & Re-operation & Death \\
\hline \multicolumn{9}{|c|}{ Infective endocarditis: } \\
\hline MM & No & $5 \mathrm{mo}$ & PS & Staph. epidermidis & Yes & Yes, unsuccessful & Yes & \\
\hline MM & No & $3 y$ & PR & $\begin{array}{l}\text { Tonsillitis, incompli- } \\
\text { ance, Staph. aureus }\end{array}$ & Yes & & & Yes (sepsis) \\
\hline$\overline{S E}$ & No & $2 y$ & PS & $\begin{array}{c}\text { Poor dental hygiene, } \\
\text { incompliance, Staph. } \\
\text { aureus }\end{array}$ & & Yes, unsuccessful & & $\begin{array}{l}\text { Yes (sepsis, } \\
\text { multiorgan } \\
\text { failure) }\end{array}$ \\
\hline MM & No & $6 y$ & PR & $?$ & & & Yes & \\
\hline$M M$ & No & $3 y$ & PS & $\begin{array}{l}\text { Infective diarrhea, En- } \\
\text { terococcus faecalis }\end{array}$ & & Yes, successful & & \\
\hline$M M$ & No & $2 y$ & $P S+P R$ & Dental procedure & & & Yes & \\
\hline$M M$ & Yes & $4 y$ & PS & Dental procedure & & & Yes & \\
\hline \multicolumn{9}{|c|}{ Valve mismatch due to the increased body mass: } \\
\hline$M M$ & No & $2 y$ & PS & Body mass increase (31 & vs. 45) & Yes, unsuccessful & Yes & \\
\hline
\end{tabular}

$M M$ - Melody Medtronic valve, SE - Sapien Edwards valve, mo - month, y-year, PS - pulmonary stenosis, PR - pulmonary regurgitation, incompliance - risky behavior and incompliance with IE prevention.

tion and a relatively wide RVOT. Thus, after 3 years of using only $\mathrm{MM}$, we introduced $\mathrm{SE}$, which enabled us to be one of the first in the world to extend the indications for TPVI from patients with dysfunctional full pulmonary conduits to those with patched RVOT $[6,7]$. In patients with borderline large RVOT dimensions (28-29 mm), we used to implant bare metal stents 2 months before valve insertion to allow for proper stent fixation as a result of tissue ingrowth. This technique enabled us to apply TPVI in patients who potentially are the most numerous group of candidates for pulmonary valve implantation, as they had PR immediately after operations performed in childhood.

\section{Early results}

The pulmonary valve competence was restored in almost all patients, after implantation of both $M M$ and SE valves. Mild regurgitation was observed in 2 patients with severe stenosis of calcified homografts. It is worth pointing out that as early as 1 month after TPVI, a tremendous decrease in RVEDVi was observed in the group of patients with PR, as well as NYHA class improvement, while RVEF increased less significantly.

Functional improvement (RVEF, peak $\mathrm{VO}_{2}$ ) was more impressive in patients with pulmonary stenosis than in those with pulmonary regurgitation. These results are consistent with other reports and suggest irreversible RV damage caused by long-term volume overload [8-10]. Pulmonary valve implantation based on right ventricle volumetric thresholds does not guarantee a complete postoperative right ventricular function restoration, but on the other hand, a significant improvement is possible even in patients with prominently increased RVEDVi $[9,11,12]$.
Patients with significant TR accompanying pulmonary valve dysfunction usually are referred for surgery. Our observations confirm previous studies that showed a reduction of TR in even $65 \%$ of patients over 5 years of follow-up $[13,14]$. We agree with Alkashkari et al. that these observations will lead to the extension of indications for TPVI [5].

\section{Long-term follow-up}

In many reports concerning TPVI, it is emphasized that short observations and little experience with used biological valves do not allow one to assess the durability of MM and SE applied percutaneously. Freedom from reintervention is reported to be $100-68 \%$ over a mean follow-up of 2 and 4.5 years, respectively [15-17]. Our observation showed that in long-term follow-up, the only factor influencing freedom from reintervention/reoperation was IE.

Although IE affected 6 patients with MM and only 1 with SE, we did not find a significant difference in the risk of IE between these valves. We restrained from comparing them hemodynamically because $M M$ valves are implanted mainly in patients with narrowed, calcified conduits and therefore with dominant pulmonary stenosis. In contrast, SE valves are implanted in wide outflow tracts, mainly in the setting of severe pulmonary regurgitation. Based on the difference, a reliable comparison of the hemodynamic indices of both valves, including the pulmonary gradient itself, is impossible.

There were no features of valve damage in any patient who did not undergo IE. Pulmonary gradient, valve competence, RV volume, and RVEF were stable during mean 5.5 years observation, though no further improvement was observed. It is worth underlining that an improve- 
ment in exercise capacity was observed after 1 year, and it continued to grow in 2-3 years after TPVI. Pregnancy, regarded as a risk factor of the degenerative process of biologic valves, did not have any impact on MM and SE valves in our patients.

\section{Complications}

It is noteworthy that 100 procedures were performed with no periprocedural deaths. Thanks to the precise assessment of the potential relationship of the expanded conduit to the coronary arteries, there were no complications related to coronary artery compression, which is the most frequent cause of periprocedural mortality $[18,19]$. We did not observe another frequent complication - late valve stent fracture. We suggest that the routine prestenting may be protective against this complication [20].

Our experience with 2 cases of SE XT valve wedging in tricuspid chordae resulting in tricuspid valve damage and the necessity of urgent operation was not something uncommon [21]. The uncovered valve is introduced into the pulmonary artery in a short sheath or relatively stiff delivery system, which may result in tricuspid valve injury. The use of a long large-bore sheath covering the valve stent may prevent severe complications, including tear of the tricuspid valve [22].

Stent migration during valve implantation in a patient with a borderline size outflow tract convinced us that a two-step procedure in patients with no waist after prestenting or with a borderline size outflow tract allows proper fixation of the stent and safe valve implantation at least 2 months later [23]. Since 2011 we have performed several two-step procedures in patients with a relatively wide RVOT without complications.

The risk of homograft rupture or dissection is reported to be high (up to $9 \%$ ) but not always associated with hemodynamic compromise as it was observed in one of our $2(2 \%)$ cases $[24,25]$. The risk is higher in patients with severe pulmonary stenosis with extensive calcification of homograft. Proper patient selection is essential to avoid this complication.

Despite encouraging early outcomes, IE is the most severe late complication of TPVI. In our cohort, the majority of the cardiovascular events (reintervention or death) that occurred during follow-up originated from IE. There are various factors debated to be associated with the increased risk of developing IE (i.e., type of valve, RVOT gradient, history of IE). However, due to the considerably small size of the cohort, these observations did not achieve statistical significance. Our study confirmed the role of severe pulmonary stenosis and suboptimal PG reduction as significant risk factors of developing IE [26]. A striking observation in our group was the considerably frequent history of infection (i.e., dental) preceding IE, which is in line with the previous research. These observations highlight the importance of IE prevention in this group and provide further evidence that in post-TPVI patients, sufficient education and IE prophylaxis are essential $[26,27]$. The effectiveness of lifetime antiplatelet therapy requires further observation. In our study, the incidence of IE was higher in the group of patients who discontinued antiplatelet therapy after 6 months rather than taking ASA permanently, but these groups cannot be compared due to different observation times.

\section{Limitations}

Some data were not available in the follow-up (irregular reporting of patients). Not all patients were examined with cardiac MRI. Compared groups had a different size and follow-up duration. The number of patients with IE was too small to determine possible risk factors and prove the effectiveness of lifetime antiplatelet therapy.

\section{Conclusions}

TPVI is a safe and effective method of treatment in patients with RVOT dysfunction after surgical repair of congenital heart defects, allowing for an immediate return to normal activity. A spectacular decrease of RVEDVi after TPVI is not parallel to functional improvement, which is more common in patients with pulmonary stenosis rather than regurgitation. RVEDVi should not be a major factor in the qualification of patients for TPVI. A favorable outcome depends on the disqualification of patients with massive calcification of a very narrow homograft, earlier prestenting in the case of a borderline wide RVOT, and rigorous IE prevention. The use of antiplatelet therapy and lifetime treatment with aspirin, in addition to the optimal reduction of the pulmonary gradient, may be important in the prevention of IE.

\section{Conflict of interest}

Prof. Marcin Demkow serves as a proctor for Medtronic and Edwards. The other authors declare no conflict of interest.

\section{References}

1. Ruzyllo W, Wlodarska EK, Demkow M, et al. Transvascular pulmonary valve implantation - early results of the first Polish experience. Adv Interv Cardiol 2009; 5: 7-17.

2. Baumgartner H, Bonhoeffer P, De Groot NMS, et al. ESC Guidelines for the management of grown-up congenital heart disease (new version 2010). Eur Heart J 2010; 31: 2915-57.

3. Biernacka EK, Demkow M, Kuśmierczyk M, Rużyłło W. Compressed valve in a calcified right ventricular outflow tract. Adv Interv Cardiol 2013; 9: 294-5.

4. Chatterjee A, Bajaj NS, McMahon WS, et al. Transcatheter pulmonary valve implantation: a comprehensive systematic review and meta-analyses of observational studies. J Am Heart Assoc 2017; 6: e006432. 
5. Alkashkari W, Alsubei A, Hijazi ZM. Transcatheter pulmonary valve replacement: current state of art. Curr Cardiol Rep 2018; 20: 27.

6. Momenah TS, El Oakley R, Al Najashi K, et al. Extended application of percutaneous pulmonary valve implantation. J Am Coll Cardiol 2009; 53: 1859-63.

7. Demkow M, Ruzyllo W, Biernacka EK, et al. Percutaneous Edwards SAPIEN (TM) valve implantation for significant pulmonary regurgitation after previous surgical repair with a right ventricular outflow patch. Catheter Cardiovasc Interv 2014; 83: 474-81.

8. Frigiola A, Tsang V, Bull C, et al. Biventricular response after pulmonary valve replacement for right ventricular outflow tract dysfunction: is age a predictor of outcome? Circulation 2008; 118: S182-90.

9. Oosterhof T, van Straten A, Vliegen HW, et al. Preoperative thresholds for pulmonary valve replacement in patients with corrected tetralogy of Fallot using cardiovascular magnetic resonance. Circulation 2007; 116: 545-51.

10. Therrien J, Provost $\mathrm{Y}$, Merchant N, et al. Optimal timing for pulmonary valve replacement in adults after tetralogy of Fallot repair. Am J Cardiol 2005; 95: 779-82.

11. Geva T. Indications for pulmonary valve replacement in repaired tetralogy of Fallot the quest continues. Circulation 2013; 128: 1855-7.

12. Egbe AC, Banala K, Vojjini R, et al. The applications and potential limitations of right ventricular volumes as surrogate marker in tetralogy of fallot. Int J Cardiol Heart Vasc 2020; 26: 100430.

13. Jones TK, Rome JJ, Armstrong AK, et al. Transcatheter pulmonary valve replacement reduces tricuspid regurgitation in patients with right ventricular volume/pressure overload. J Am Coll Cardiol 2016; 68: 2244.

14. Hascoet S, Dalla Pozza R, et al. Early outcomes of percutaneous pulmonary valve implantation using the Edwards SAPIEN 3 transcatheter heart valve system. Eurolntervention 2019; 14: 1378-85.

15. Plessis J, Hascoët S, Baruteau A, et al. Edwards SAPIEN transcatheter pulmonary valve implantation: results from a French Registry. JACC Cardiovasc Interv 2018; 11: 1909-16.

16. Nordmeyer J, Ewert P, Gewillig M, et al. Acute and midterm outcomes of the post-approval MELODY Registry: a multicentre registry of transcatheter pulmonary valve implantation. Eur Heart J 2019; 40: 2255-64.

17. Borik S, Crean A, Horlick E, et al. Percutaneous pulmonary valve implantation: 5 years of follow-up does age influence outcomes? Circ Cardiovasc Interv 2015; 8: e001745.

18. Eicken A, Ewert P, Hager A, et al. Percutaneous pulmonary valve implantation: two-centre experience with more than $100 \mathrm{pa}$ tients. Eur Heart J 2011; 32: 1260-5.

19. Morray BH, McElhinney DB, Cheatham JP, et al. Risk of coronary artery compression among patients referred for transcatheter pulmonary valve implantation a multicenter experience. Circ Cardiovasc Interv 2013; 6: 535-42.

20. Demkow M, Biernacka EK, Spiewak M, et al. Percutaneous pulmonary valve implantation preceded by routine prestenting with a bare metal stent. Circ Cardiovasc Interv 2011; 77: 381-9.

21. Faccini A, Butera G. Tricuspid regurgitation as a complication of Edwards Sapien XT valve implantation in pulmonary position a problem to deal with. Catheter Cardiovasc Interv 2018; 91: 927-31.
22. Hascoet S, Karsenty C, Tortigue M, et al. A modified procedure for percutaneous pulmonary valve implantation of the Edwards SAPIEN 3 valve. Eurolntervention 2019; 14: 1386-8.

23. Bertels RA, Blom NA, Schalij MJ. Edwards SAPIEN transcatheter heart valve in native pulmonary valve position. Heart 2010; 96: 661.

24. Berman DP, McElhinney DB, Vincent JA, et al. Feasibility and short-term outcomes of percutaneous transcatheter pulmonary valve replacement in small $(<30 \mathrm{~kg})$ children with dysfunctional right ventricular outflow tract conduits. Circ Cardiovasc Interv 2014; 7: 142-8.

25. Biernacka EK, Ruzyllo W, Demkow M, et al. Transcatheter pulmonary valve implantation in patients with right ventricular outflow tract dysfunction: early and mid-term results. J Invasive Cardiol 2015; 27: E82-9.

26. McElhinney DB, Sondergaard L, Armstrong AK, et al. Endocarditis after transcatheter pulmonary valve replacement. J Am Coll Cardiol 2018; 72: 2717-28.

27. Abdelghani M, Nassif M, Blom NA, et al. Infective endocarditis after melody valve implantation in the pulmonary position: a systematic review. J Am Heart Assoc 2018; 7: e008163. 